TPeriodica Polytechnica Civil Engineering

62(4), pp. 901-910, 2018

https://doi.org/10.3311/PPci.11570

Creative Commons Attribution (i)

RESEARCH ARTICLE

\section{Effects of Asphalt Binder Modifying with Polypropylene on Moisture Susceptibility of Asphalt Mixtures with Thermodynamically Concepts}

\author{
Gholam Hossein Hamedi ${ }^{*}$, Ali Reza Azarhoosh², \\ Mojtaba Khodadadi ${ }^{3}$ \\ Received 06 October 2017; Revised 16 February 2018; Accepted 18 April 2018
}

\begin{abstract}
In this study, the effect of using Polypropylene (PP) as an antistripping additive of asphalt mixtures is investigated. Here, the moisture susceptibility of asphalt mixtures is evaluated by determining the micro-mechanisms using the surface free energy (SFE) concept. The adhesion bond between the aggregate and asphalt binder and the cohesion strength of the asphalt binder are considered as the main factors that affect moisture damage of asphalt mixtures. Test results indicate that the use of PP improves the resistance of asphalt mixtures in both wet and dry conditions. Also, the results of the SFE tests showed that the modifying asphalt binder with PP increases free energy of adhesion that will improve adhesion resistance between asphalt binder-aggregates. The amount of debonding energy in the samples which are modified with PP is lower than the control samples. This shows that by modifying asphalt binders, the tendency of asphalt binder-aggregate stripping can be reduced. The results show the total SFE of the asphalt binders of the modified samples have more free energy rather than the control samples. This phenomenon shows that failure in the asphalt binder film and cohesion failure will be happened more rarely.
\end{abstract}

\section{Keywords}

asphalt mixtures, moisture damage, antistripping additive, polypropylene, surface free energy, modified Lottman test

\footnotetext{
1 Department of Civil Engineering

Faculty of Engineering,

University of Guilan

P.O.Box 3756, Rasht, Iran

2 Department of Civil Engineering

Faculty of Engineering,

University of Bojnord

PC 9453155111, Bojnord, Iran

3 Department of Civil \& Environmental Engineering,

Amirkabir University of Technology

424 Hafez Ave, Tehran, Iran

*Corresponding author, email: hamedi@guilan.ac.ir
}

\section{Introduction}

Moisture damage can be defined as the loss of strength and durability in asphalt mixtures due to the effect of moisture. Moisture damage in the asphalt mixtures is a common concern which occurs because of the high repair and maintenance costs of the pavements $[1,2]$.

In general, moisture damage is occurred because of two main reasons including loss of adhesion and loss of cohesion [3]. On the other hand, moisture damage occurs because moisture has less viscosity and surface tension in comparison with the asphalt binder [4]. This leads the aggregates to tend to be adjacent water rather than the asphalt binder which makes the stripping to be happened. This occurrence is gradually shown in the Fig. 1. In this figure, one asphalt binder drop is in contact with the surface of the aggregate and all the system has been submerged in water. The contact angle $(\theta)$ between asphalt binder and aggregate at the presence of water will be reduced by passing the time. This process continues till the angle gets increased until the asphalt binder loses its contact with the aggregate surface; i.e. $(180-\theta)$ will be decreased $[5,6]$.

Moisture damage has been noticed by the researchers for many years, but many aspects of this damage are yet unknown [7]. There are two significant questions related to this topic:

1) Approaches that can reduce moisture damage intensity

2) Approaches to precisely predict the condition of the moisture damage potential $[8,9]$.

Nowadays, the need to incorporate new materials in the structure of the asphalt mixtures is sensible. These materials are supposed to reduce moisture damage due to some reasons including: expansion of the pavement network, increase of the traffic intensity, existence of the huge and heavier trucks and at some points and more intense environmental conditions [10-14].

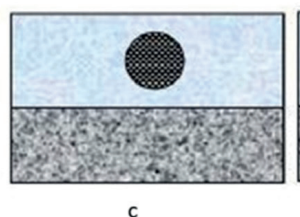

c

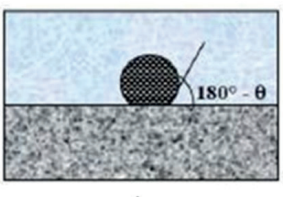

b

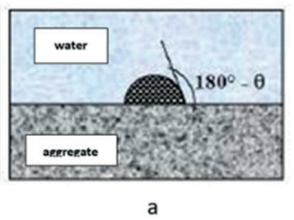

Fig. 1 Phases of asphalt binder's separation from the surface of the aggregate as a result of the presence of water [5] 
There are two methods to improve adhesion between aggregate and asphalt binder that will cause a reduction of moisture damage in asphalt mixtures as a sequence. The first method is using liquid antistripping additive in asphalt binder to improve the cohesion of asphalt binder and asphalt binder-aggregate adhesion. Liquid antistripping materials are in fact chemical surfactants that increase the adhesion between asphalt binder-aggregate by changing the structure of the asphalt binder. Also, these types of additives increase the coating ability of asphalt binder around the aggregates. The main raw materials of the liquid antistripping additives are obtained from the family of amines and amid-amines [13]. The second method is to coat aggregate surface using appropriate materials which alter the surface properties of aggregates. By applying this method the hydrophilic tendency of acidic aggregates will be decreased. Thus, when the water enters to the asphalt binder-aggregate system, the intensity of stripping will be reduced. One of the most popular materials in this category is hydrated lime $[15,16]$.

Although mentioned materials reduce the moisture in asphalt mixtures; using these materials makes some technical problems [17-22]. According to the considered problems, this research tried to analyse the utilization of the polymers as an antistripping material.

\subsection{Problem statements and objectives}

The most imperative purpose of this investigation is to increase the resistance of asphalt mixtures against moisture damage. In order to accomplish that, the materials of asphalt mixtures are modified in order to increase the resistance of mixtures. According to the literature review, it can be seen that the most effective way to create asphalt mixtures resistant to moisture damage is using antistripping materials. Many additives are studied to be feasible in asphalt mixtures, some key factors like making asphalt mixtures resistant to moisture (the most important purpose of this study), non-existent issues in other technical specifications of the mixture, performance considerations, economic considerations and environmental considerations are found to be most significant parameters for designers.

The most important objectives of the present study are:

- Effect of PP additive incorporation on asphalt binder cohesion

- Effect of PP additive incorporation on the adhesion of asphalt binder-aggregate in dry and wet conditions improvement

- Effect of PP additive incorporation on resistance of asphalt mixtures in dry and wet conditions according to mechanical experiments

- Effect of PP dosage on moisture damage of asphalt mixture

\subsection{Literature review}

There are a few researches that studied the direct effect of material characterization on the moisture damage. Some studies of these literatures are about the parameters that can be obtained directly from material characterization performed. Griffith [23] showed that the minimum energy required crack growth in elastic materials is a function of the SFE which in terms of number is equal to their surface tension. Schapery [24] utilized a method similar to Griffith in order to develop the basis of crack growth in the viscoelastic materials. According to the results and the energy balance method, a fundamental property of the material is continuity of the cohesion energy to determine the work. Free cohesion energy is the amount of the needed energy to create two surfaces with a unit area in a material which is equal to two SFE of the material from the formula point of view. Kim et al. [24] in their research showed that how mastic resistance to micro cracks is significantly related to the amount of the exterminated energy by mastic.

In a comprehensive study that was conducted by Cheng [25] general study in the concepts of SFE and its application in asphalt pavements was performed. Cheng showed that the system's energy reductions in the presence of water and moisture damage in asphalt mixtures are related to each other directly during the stripping (free energy). In another study, Bhasin et. al. [26] studied two parameters affecting the connection energy-adhesion and connection strength between aggregate and asphalt binder. The researcher also monitored the reduction of energy released when the aggregates is exposed in asphalt binder in the presence of water, by using SFE values. These parameters limit values for asphalt-aggregate mixtures susceptible to moisture failure by comparing these amounts with field performance. Masad et. al. [27] investigated the moisture damage of asphalt mixtures using the concept of a mechanism that influences the adhesion between aggregate-asphalt binder of the free cohesion energy or mastic and the detachment of viscoelastic materials. The free adhesion and cohesion energy is measured using the components of the SFE of asphalt binder and aggregate.

In 2006, Bhasin [27] studied the important characteristics that influence the moisture damage of the asphalt mixtures. The author also developed laboratory equipment and then, they performed an analytical review to determine these characteristics. Bhasin et. al. [28] measured the amount of energy required for stripping. Based on the results presented in this study, it was found that if the moisture content is at the surface between asphalt binder-aggregate, stripping in both asphalt binder and aggregate will occur due to the work of adhesion or Gibbs free energy in the presence of water and are negative in values. An investigation at the Department of Transportation's Federal Research Report examined the effect of free energy of aggregates and asphalt binder on asphalt mixture's resistance against moisture damage [29].

Four Energy parameters are presented in NCHRP 9-37 report, based on measurements of the components of the SFE. Moisture susceptibility of all combinations of asphalt binder and aggregate has been introduced as functions of four energy parameters as independent factors. These energy parameters can be extracted 


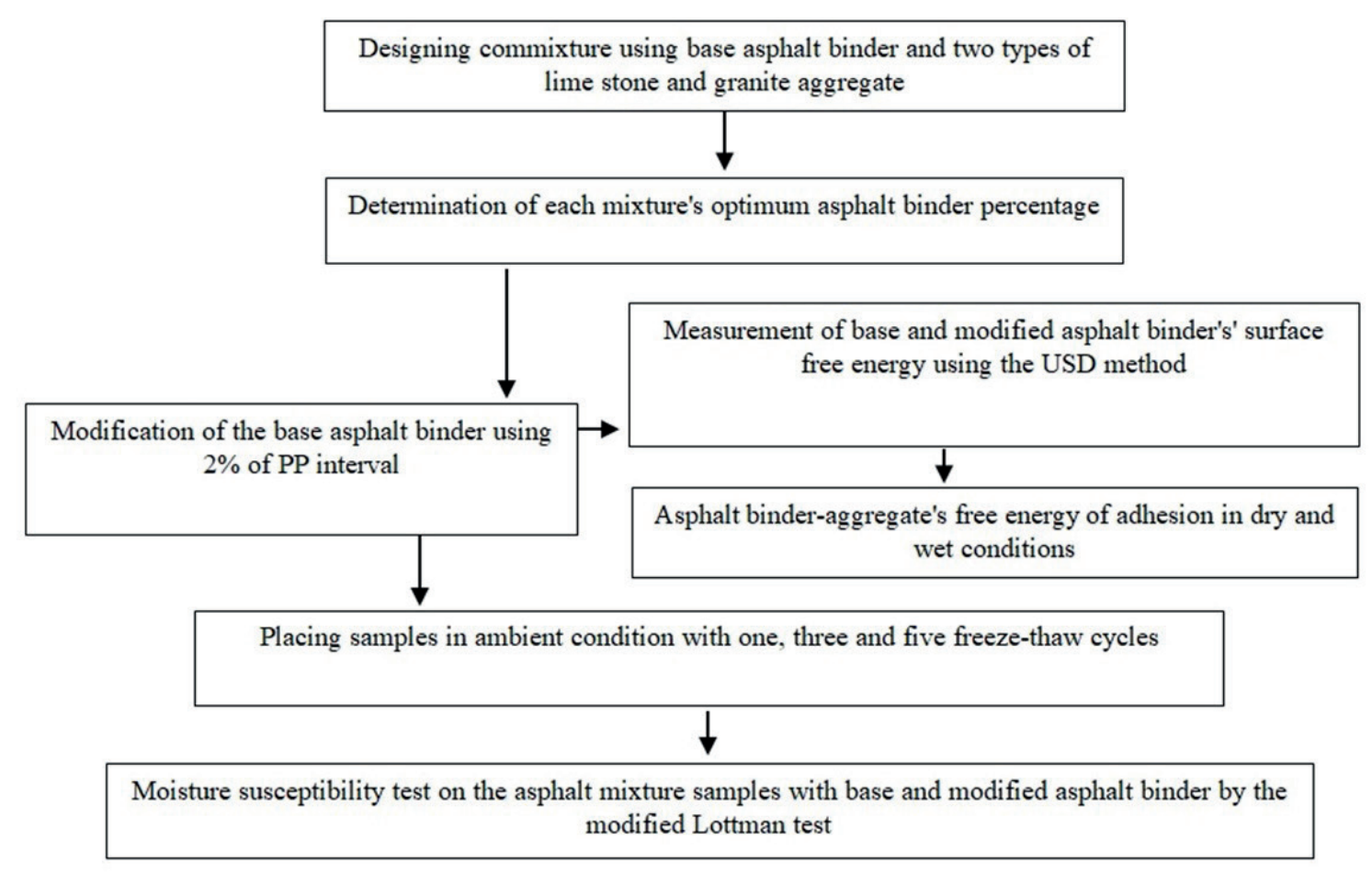

Fig. 2 Flow chart of experimental design of this study

from asphalt binder and aggregates' SFE [30]. In a study by Kim et. al. [31], the small cracks in the system caused by repetitive loading asphalt binder-aggregate at high temperatures (above 40 ${ }^{\circ} \mathrm{C}$ ) and analysis of moisture damage based on the theory of SFE, were examined. In this study, a percentage of aggregate surface that stripped in loading cycles as an index to determine the potential of moisture damage in asphalt mixtures has been considered. This index is obtained from aggregates and asphalt binder using SFE and repetitive loading. A report in 2005 by Lytton et. al. [32] examined the moisture damage using SFE measurements and dynamic mechanical analysis. The results of the SFE are used to assess the cohesion of asphalt binder and the adhesion of asphalt binder-aggregate. This study has offered a development of a new method for data analysis and calculate dynamic mechanical failure rate. There was an effort to provide free surface energy indexes that are associated with moisture damage occurrence. In this study, SFE components of 8 and 4 types of aggregates and asphalt binders were determined, respectively. The results of this study indicate that cohesion free energy, free energy of asphalt binder-aggregate adhesion, the system's released energy (energy released by system) in the presence of stripping (debonding energy), aggregates' specific surface area and coating capability are of the most important parameters effective in the occurrence of moisture damage [33].

\section{Experimental Design}

\subsection{Experimental set up}

Flowchart of experimental design of this study is presented in Fig. 2. Asphalt concrete samples are prepared for testing under controlled conditions which consists of two stages: heating aggregate and asphalt binder separately, mixing and compressing.
In the following flowchart, experimental program to prepare and test conventional and modified asphalt binder samples is shown. In accordance with previous studies, it has been found that the percentage of polymer has little effect on the optimum asphalt content. Since, the optimum asphalt binder percentage of control sample is selected as a dosage of the modified sample [34].

\subsection{Materials}

The asphalt binder used in this study has a penetration grade of $60 / 70$ that is obtained from Isfahan's oil refinery plant (Table 1).

Two types of aggregates with different characteristics against moisture damage have been incorporated in this research: limestone that serves as a hydrophobic aggregate and granite known as a hydrophilic and sensitive aggregate to moisture damage.

Table 1 The properties of the base asphalt binder used in this study

\begin{tabular}{lcc}
\hline Test & Standard & Result \\
\hline Penetration $\left(100 \mathrm{~g}, 5 \mathrm{~s}, 25^{\circ} \mathrm{C}\right), 0.1 \mathrm{~mm}$ & ASTM D5 & 66 \\
Penetration $\left(200 \mathrm{~g}, 60 \mathrm{~s}, 4^{\circ} \mathrm{C}\right), 0.1 \mathrm{~mm}$ & ASTM D5 & 24 \\
Penetration ratio & ASTM D5 & 0.36 \\
Ductility $\left(25^{\circ} \mathrm{C}, 5 \mathrm{~cm} / \mathrm{min}\right), \mathrm{cm}$ & ASTM D113 & 110 \\
Solubility in trichloroethylene, $\%$ & ASTM D2042 & 98.8 \\
Softening point, ${ }^{\circ} \mathrm{C}$ & ASTM D36 & 54 \\
Flash point, ${ }^{\circ} \mathrm{C}$ & ASTM D92 & 268 \\
Loss of heating, $\%$ & ASTM D1754 & 0.74 \\
Properties of the TFOT Residue & & \\
Penetration $\left(100 \mathrm{~g}, 5 \mathrm{~s}, 25^{\circ} \mathrm{C}\right), 0.1 \mathrm{~mm}$ & ASTM D5 & 61 \\
Specific gravity at $25{ }^{\circ} \mathrm{C}, \mathrm{g} / \mathrm{cm} 3$ & ASTM D70 & 1.03 \\
Viscosity at $135^{\circ} \mathrm{C}, \mathrm{cSt}$ & ASTM D2170 & 157.9 \\
\hline
\end{tabular}


Table 2 Chemical composition of the two types of aggregates

\begin{tabular}{lcc}
\hline Test & Granite & Limestone \\
\hline $\mathrm{pH}$ & 6.9 & 7.2 \\
Silicon dioxide, $\mathrm{SiO}_{2}(\%)$ & 62.7 & 2.3 \\
Aluminum oxide, $\mathrm{Al}_{2} \mathrm{O}_{3}(\%)$ & 19.7 & 9.7 \\
Ferric oxide, $\mathrm{Fe}_{2} \mathrm{O}_{3}(\%)$ & 2.3 & 6.8 \\
Magnesium oxide, $\mathrm{MgO}(\%)$ & 1.8 & 3.5 \\
Calcium oxide, $\mathrm{CaO}(\%)$ & 4.4 & 71.2 \\
\hline
\end{tabular}

Table 3 Physical properties of the two types of aggregates

\begin{tabular}{|c|c|c|c|c|}
\hline Test & Standard & Granite & Limestone & $\begin{array}{c}\text { Specification } \\
\text { limit }\end{array}$ \\
\hline $\begin{array}{l}\text { Specific gravity } \\
\text { (coarse agg.) }\end{array}$ & $\begin{array}{c}\text { ASTM C } \\
127\end{array}$ & & & \\
\hline Bulk & & 2.652 & 2.612 & - \\
\hline Saturated surface dry & & 2.664 & 2.644 & - \\
\hline Apparent & & 2.686 & 2.663 & - \\
\hline $\begin{array}{l}\text { Specific gravity } \\
\text { (fine agg.) }\end{array}$ & $\begin{array}{c}\text { ASTM C } \\
128\end{array}$ & & & \\
\hline Bulk & & 2.652 & 2.619 & - \\
\hline Saturated surface dry & & 2.656 & 2.638 & - \\
\hline Apparent & & 2.681 & 2.659 & - \\
\hline $\begin{array}{l}\text { Specific gravity } \\
\text { (filler) }\end{array}$ & $\begin{array}{c}\text { ASTM } \\
\text { D854 }\end{array}$ & 2.659 & 2.649 & - \\
\hline $\begin{array}{l}\text { Los Angeles } \\
\text { abrasion (\%) }\end{array}$ & $\begin{array}{c}\text { ASTM C } \\
131\end{array}$ & 21 & 27 & $\operatorname{Max} 45$ \\
\hline $\begin{array}{l}\text { Flat and elongated } \\
\text { particles }(\%)\end{array}$ & $\begin{array}{c}\text { ASTM D } \\
4791\end{array}$ & 5.9 & 8.4 & $\operatorname{Max} 10$ \\
\hline $\begin{array}{l}\text { Sodium sulphate } \\
\text { soundness }(\%)\end{array}$ & $\begin{array}{c}\text { ASTM } \\
\text { C } 88\end{array}$ & 2.3 & 3.9 & Max 10-20 \\
\hline $\begin{array}{l}\text { Fine aggregate } \\
\text { angularity }\end{array}$ & $\begin{array}{c}\text { ASTM C } \\
1252\end{array}$ & 51.8 & & $\operatorname{Min} 40$ \\
\hline
\end{tabular}

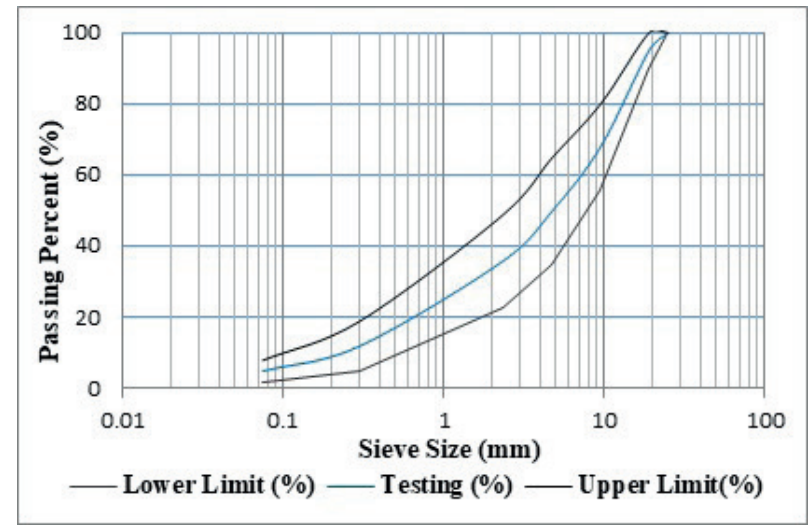

Fig. 3 The aggregate grading of the study

In this table, only the minerals with high percentage and minerals that are important at determining the hydrophobic and hydrophilic ability of aggregates are presented. The physical characteristics of aggregates and the results of quality control of mines that are fabricated with materials which are used in this study are presented in the Table 3. The main reason for using these types of aggregates is their different hydrophilic ability. Since, the effect of hydrophilic ability of aggregates on moisture damage can be assessed.

The grading of the aggregates used in this is shown in the in Fig. 3.

\subsection{Additives}

Also known as PP, Polypropylene (-[CH2-CH (CH3)] n-) is one of the most widely used and most basic polymers in the world and is the largest consumer of propylene. Polypropylene is made from propylene polymerization in room temperature and pressure in the presence of known catalyst Ziegler-Natta. The presence of this catalyst, create an isotactic polymer that can be crystallize up to 90 percent.

In this study, the PP is used by two weight percentages of $2 \%$ and $4 \%$ of asphalt binder's weight. The reason for these levels of replacing selection is because of the most of previous studies which incorporated polymer additives; the replacing level is usually between 1 to 8 percent of the asphalt binder by weight. To add this material to the asphalt binder, first the asphalt binder should be heated to $160^{\circ} \mathrm{C}$ in order to reduce viscosity and increase the mixing ability with the polymer in the mixer. Mixing the asphalt binder and polymer was continued for 6 minutes and with rotation speed of $8000 \mathrm{rpm}$.

\section{Experimental setup and procedure \\ 3.1 Moisture sensitivity test (AASHTO T283)}

AASHTO T283 is a common test to control resistance of asphalt mixtures against moisture damage and to evaluate the efficiency of antistripping. The required materials are mixed to produce dry and wet samples of HMA in the optimum asphalt binder percentage. More samples are required when one of the samples is destroyed or the maximum amounts of the samples' density are not identified. The target air voids percentage of 7 \pm 1 is determined in accordance with AASHTO T269 standard which this target is achieved by applying the definite number of blows. Afterwards, the samples are divided into dry and wet samples. The wet samples have been then subjected to reach the saturation mole of $55-80 \%$. Saturated samples are kept for 16 hours in a freezer at $-18^{\circ} \mathrm{C}$ and then for 24 hours in a water bath maintained at a temperature of $60^{\circ} \mathrm{C}$ while the others are kept in dry conditions. All of the samples are brought into the laboratory temperature of $25^{\circ} \mathrm{C}$ and the indirect tensile strength test is conducted on the samples. The method of testing and loading conditions is shown in the Fig. 4.

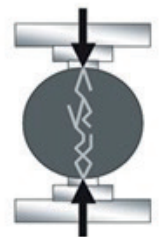

Fig. 4 The procedure of loading and performing the experiment in the indirect tensile test 
The indirect tensile amount is achieved through the following equation:

$$
S=\frac{2 P}{\Pi D t}
$$

Where, $P$ describes the maximum applied vertical load, $D$ is the samples diameter and $t$ defines the samples thickness.

Tensile Strength Ratio (TSR) is achieved by the following equation:

$$
T S R=100\left(\frac{S_{\text {cond }}}{S_{\text {uncond }}}\right)
$$

Where, $S_{\text {cond }}$ is the average of the indirect tensile resistance of the samples under the wet condition and $S_{\text {uncond }}$ describes the average of the indirect tensile resistance of the samples under the dry condition.

In this study, in order to determine a better effect, the polymeric material in the humid condition of the samples is done with 1, 3 and 5 freeze-thaw cycles.

a) Measuring the SFE components of the asphalt binder

The Wilhelmy plate method is utilized to measure of the SFE components of asphalt binder [35].

b) Measuring the SFE Components of Aggregate

According to the previous sections, two types of aggregates are used. It is also important to know that the SFE components of aggregate are determined by USD method [36].

\section{Results and discussion}

\subsection{Results of the experiment of moisture susceptibility}

The results of the indirect tensile strength of specimens when exposed to different cycles of freeze-thaw are shown in Fig. 5. As it can be observed, the value of the indirect tensile of the samples, with the increase of the number of freeze-thaw cycles are reduced. The reduction in indirect tensile strength of samples by increasing the number of freeze-thaw cycles can be related to adhesion or cohesion of the asphalt binder caused from more presence of the samples that were exposed to moisture. From Fig. 5, PP as antistripping material causes an increase in adhesion and cohesion in mixtures. Also it prevents asphalt binder to be moved quickly from the surface of aggregates and leads to the increase of resistance in the mixtures within freeze-thaw cycles more than in supplements of PP.

Figs. 7-8 show the amounts of the indirect tensile strength for the mixtures that are made with PP in this research. It is evident that with the increase in the number of freeze-thaw cycles, the amount of ITS is decreased. The samples made by limestone and 4\% PP have the highest amount of the indirect tensile strength ratio (92\%) in the first cycle and this amount is reduced to $84 \%$ at the fifth cycle.

The chemical mixtures of both aggregates used in this study are presented in Table 1 . This table shows that limestone is mainly consist of the Cao while the granite aggregates consist of mostly of $\mathrm{SiO}_{2}$ and $\mathrm{Al}_{2} \mathrm{O}_{3}$. The classification of the

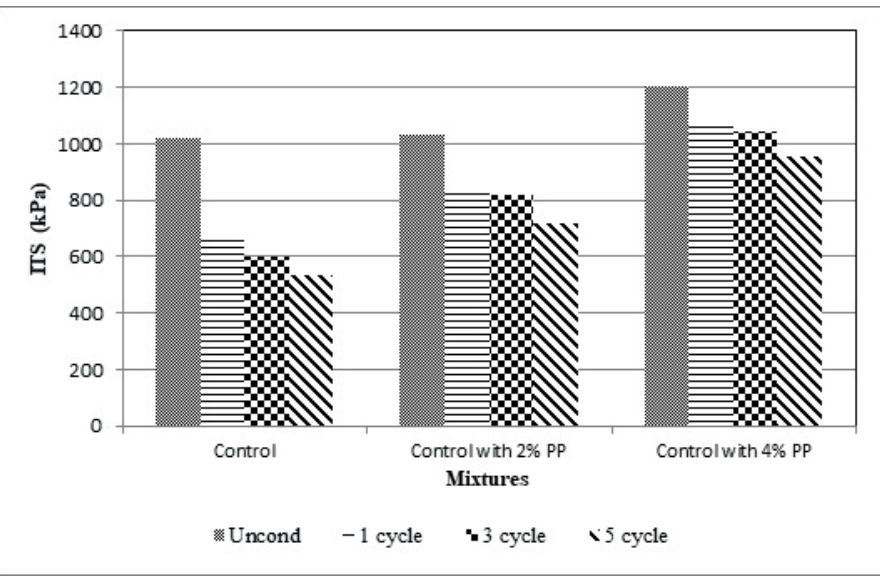

Fig. 5 ITS values of control and modified samples with PP addition in different freeze-thaw cycles made with granite aggregate

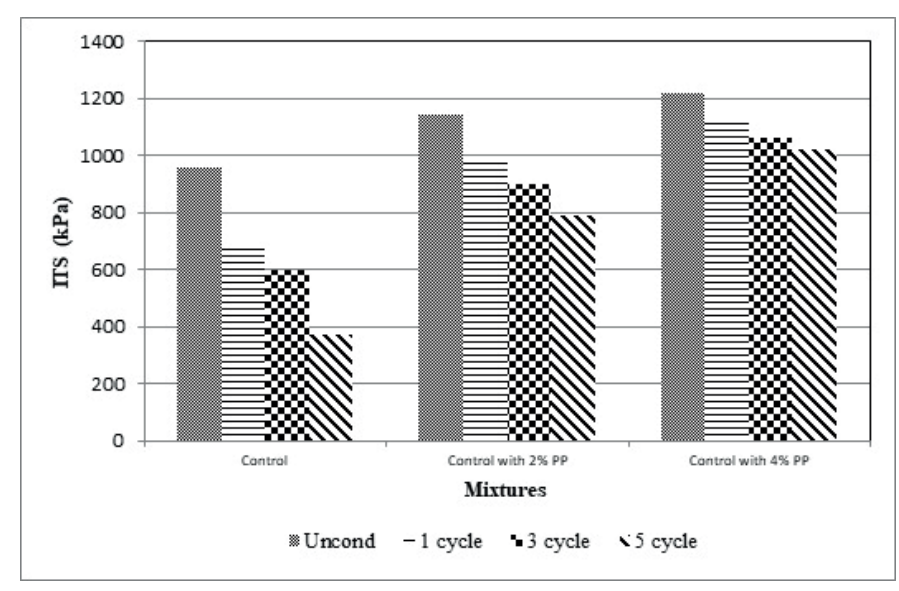

Fig. 6 ITS values of control and modified samples with PP addition in different freeze-thaw cycles made with limestone aggregate

aggregates is like the limestone aggregate and granite aggregates are considered hydrophilic. Using the method of Figs. $7-8$, it can also be identified that limestone, in comparison with granite aggregate, provides stronger mixtures against moisture. According to indirect tensile test result, the tensile resistances of dry samples are significantly reduced due to various circumstances, and this shows that the moisture damage is because of water presence. This reduction is more considerable for the modified samples in comparison with control samples.

Different additives have different effects on the performance of the asphalt mixtures. The results of PP addition show that this additive material has a positive effect on the amount of the indirect tensile ratio in all of the percentages used in this study. Adding $2 \%$ of these materials significantly increases the amount of the indirect tensile rate. While this increase in $4 \%$ of additive in comparison with $2 \%$ additive is not significant; this means that the increase of more than $2 \%$ of this material is not logical, because the cost of running the mixture will be increased and it also has a positive effect on increasing resistance against moisture damage in comparison with the samples made with $2 \%$ of this material is not observed. Therefore addition of $2 \%$ PP can be considered as optimal dosage of incorporation. 


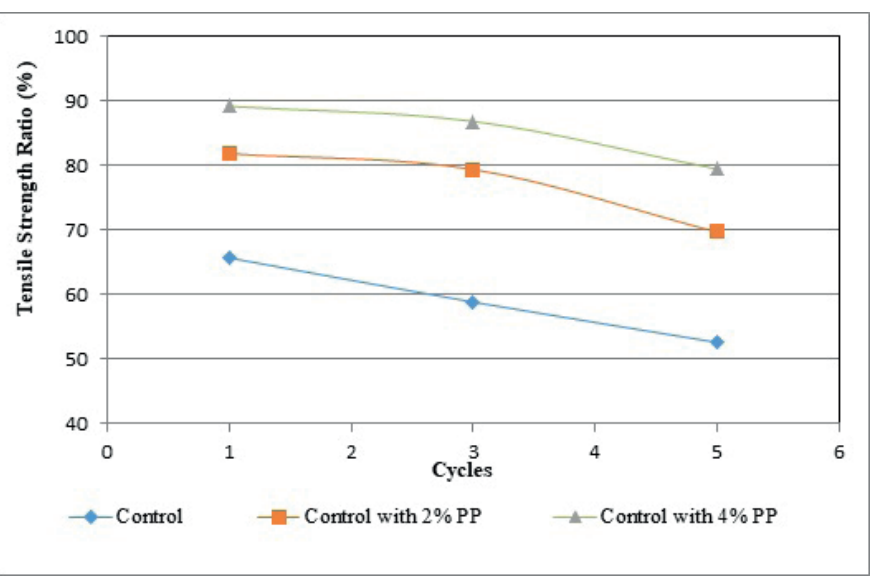

Fig. 7 TSR values of control and modified samples with PP additive in different freeze-thaw cycles made with granite aggregate

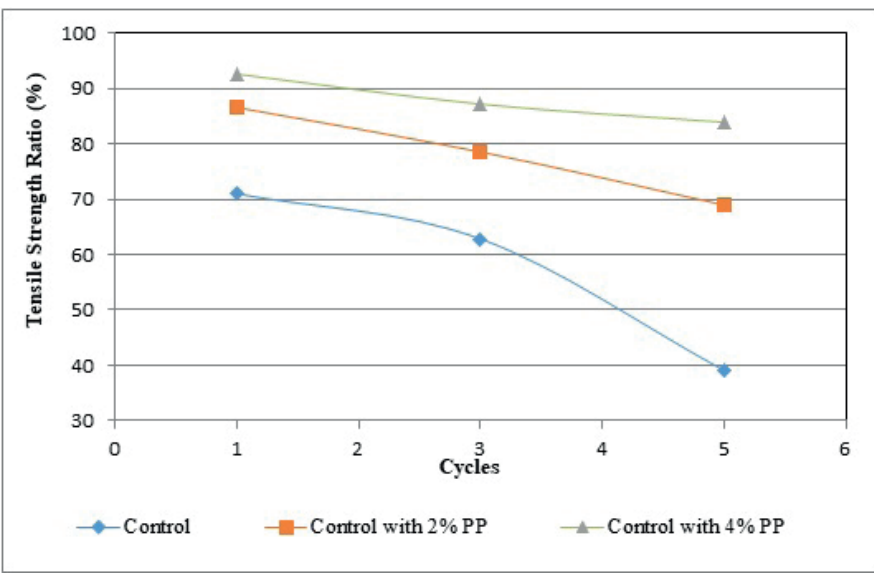

Fig. 8 TSR values of control and modified samples with PP additive in different freeze-thaw cycles made with limestone aggregate

Antistripping additives utilization dosage, based on the type of the asphalt binder and the type of the antistripping materials, are variables and the optimum percentage should be found using the experiments that are used for determination of moisture susceptibility.

In order to precisely examine the effect of the PP additive used in this investigation on the moisture susceptibility of the asphalt mixtures 1, 3, 5 freeze-thaw cycles according to AASHTO T283 standard is applied. It is observed that the reduction of the indirect tensile resistance of the modified mixtures with $\mathrm{PP}$ additive is not as much as the control mixtures in different cycles. Decreasing in the amounts of the indirect tensile rate between first and third cycles is lower than the reduction of the direct tensile rate between third and 5th cycles. This is due to the fact that with the increase of freeze-thaw cycles, antistripping of the asphalt binder from the surface of the aggregates is reduced and this causes the stripped aggregates to no longer participate in loading. The prepared samples with limestone showed the least changes in the amount of the indirect tensile rate in cycles 1 to 5 .

From the data presented in the figures below, it can be concluded that adding antistripping materials, increases adhesion and cohesion in the mixture which don't allow instant movement of the asphalt binder from the surface of the aggregates.
Consequently, modified samples reveal more resistance against moisture damage when subjected to more freeze-thaw cycles when compared to the samples with no additives.

The results presented in this study suggest that using $2 \%$ of PP material has significantly improved the resistance of asphalt mixtures against moisture damage in comparison with the control samples. Using $2 \%$ of the PP has caused the TSR index, which is considered as the practical index for moisture sensitivity in executive projects, to be more than the minimum recommended value in most regulations $(75 \%)$ and the problem of moisture sensitivity in the samples be removed from in terms of regulations. Using $4 \%$ of the PP has also resulted in further improvement in the resistance of the asphalt mixture against moisture damage, but the difference between the samples with 2 and 4\% PP is not significant. On the other hand, the cost of materials and the problems of asphalt modification is higher in the samples with $4 \%$ PP. So, it seems that using $2 \%$ PP can be recommended as the optimum content of this substance as an antistripping additive in asphalt mixtures.

\subsection{Results of the Experiments of the SFE}

The results of the SFE of the asphalt binder and its components with or without the usage of the PP material are shown in the Table 4. Asphalt binder is a single phase mixture from different molecules. These molecules are categorized into polar and nonpolar. Nonpolar molecules act as a system or a solvent for the placement of the molecules; this issue has been caused the creation of a weak system of polar-polar mixtures. This is a reason for elastic behavior of the asphalt binder. Polar molecules are monotonously distributed in the asphalt binder void that based on the heat these weak bounds are broken and the asphalt binder moves toward the transference to a Newtonian fluid. Most of the generated molecule groups have an acidic treat which makes the asphalt binder to be considered as an acidic material. As it is shown in the Table 4, the acidic and base component of the basic binder is 2.71 and 0.41 (ergs $/ \mathrm{cm} 2$ ), respectively. Considering the asphalt mixtures prepared with acidic aggregates and asphalt binder, the chemical characteristics of these surfaces don't allow the proper adhesion between these two acidic materials; since the asphalt binder is acidic.

Coating is an ability of the liquids in contact with the surface of the solid material that change the results of the contact between two materials beside together. Although this concept of adhesion has a different meaning according to some investigator's idea, it can provide the necessary condition for adhesion. From the data given in the Table 4, it can be interpreted that using PP reduces the contact angle of asphalt binder which causes the aggregates to be covered better with modification with PP asphalt binder.

Most of the aggregates have surfaces with electric load that makes a polarity on their surfaces. Asphalt binders that are mainly composed of heavy molecules of hydrocarbon weight 
Table 4 Base and modified asphalt binder's SFE components

\begin{tabular}{lccc}
\hline Asphalt binder type & $\begin{array}{l}\text { Control } \\
\text { asphalt } \\
\text { binder }\end{array}$ & $\begin{array}{c}\text { Asphalt binder } \\
\text { with 2\% PP }\end{array}$ & $\begin{array}{c}\text { Asphalt binder } \\
\text { with 4\% PP }\end{array}$ \\
\hline $\begin{array}{l}\text { Contac angle with water } \\
\text { Contact angle with }\end{array}$ & 103.30 & 95.01 & 92.72 \\
glycerol & 85.84 & 75.54 & 73.38 \\
$\begin{array}{l}\text { Contact angle with for- } \\
\text { maldehyde }\end{array}$ & 81.34 & 68.59 & 65.48 \\
$\begin{array}{l}\text { Total free energy } \\
\text { (ergs/cm }{ }^{2} \text { ) }\end{array}$ & 14.57 & 23.77 & 27.22 \\
$\begin{array}{l}\text { Non-polar free energy } \\
\text { (ergs/ } \text { cm }^{2} \text { ) }\end{array}$ & 12.46 & 21.37 & 24.76 \\
$\begin{array}{l}\text { Polar free energy } \\
\text { (ergs/cm }{ }^{2} \text { ) }\end{array}$ & 2.11 & 2.40 & 2.46 \\
$\begin{array}{l}\text { Free acidic surface energy } \\
\text { component (ergs/cm }{ }^{2} \text { ) }\end{array}$ & 2.71 & 2.29 & 0.81 \\
$\begin{array}{l}\text { Free base surface energy } \\
\text { component }\end{array}$ & 0.41 & 0.63 & \\
\hline
\end{tabular}

show less polar activity. Thus, the adhesion between asphalt binder and aggregate in this case is composed of weakened dispersed forces. It can be observed from the data given in Table 4 that PP causes an increase in the amount of asphalt binder's non-polar SFE. Increase in non-polar components of SFE makes covalent and non-polar links that might not easily be broken in the presence of water.

The results showed that the addition of PP increased the SFE of the basic part and decreased the acidic part of the SFE. These factors caused adhesion between asphalt binder and acidic aggregates.

The measurement of SFE components of asphalt binder shows that the use of PP has led to decreased and increased in the acidic and basic components of asphalt binder's SFE, respectively. Asphalt binder in the basic stage has acidic characteristics that its adhesion to acidic materials, such as granite aggregates, is complex. These changes in asphalt binder's SFE component, reduces the acidic properties and also increases base properties which increases its adhesion to acidic aggregates and improves its resistance when subjected to the water.

Comparison of the results shows that the addition of antistripping materials increases the asphalt binder's SFE. However, it has also been proved in some studies that the addition of antistripping liquid reduces the SFE [9]. The free cohesion
Table 5 Base and modified asphalt binder's SFE components

\begin{tabular}{lccccc}
\hline $\begin{array}{l}\text { Aggregate } \\
\text { type }\end{array}$ & $\begin{array}{c}\text { Total } \\
\text { SFE }\end{array}$ & $\begin{array}{c}\text { Non polar } \\
\text { component }\end{array}$ & $\begin{array}{c}\text { Polar } \\
\text { component }\end{array}$ & $\begin{array}{c}\text { Base } \\
\text { component }\end{array}$ & $\begin{array}{c}\text { Acidic } \\
\text { component }\end{array}$ \\
\hline Granite & 286.99 & 57.40 & 229.59 & 568.24 & 23.19 \\
Limestone & 286.52 & 98.90 & 187.62 & 570.32 & 15.43 \\
\hline
\end{tabular}

energy for rapture is the energy needed with unite surface in the asphalt binder membrane. According to the final results, using PP has caused the probability of the occurrence of the cracking in mastic to be decreased. The same results are found in other investigations [38].

The aggregates SFE is measured using USD method and the results are illustrated in Table 5. The results showed that as expected, limestone aggregates that are considered alkali have a bigger basic SFE component by contrast to the granite and vice versa; granite has a bigger acidic component in comparison with limestone aggregates.

According to Good's et. al. [39], the free cohesion energy is positive and the higher positive amounts showed that a better adhesion is provided. The results of the adhesion SFE between asphalt binder and the aggregates before and after the modification using PP, are shown in Table 6. These results are estimated according to the measurements that are presented in Tables 4-5 using thermodynamic principles. In all of the samples, the asphalt binder-aggregate free adhesion energy changes from a positive amount to a negative amount when exposed to water. This process is previously expected to happen because water has a bigger SFE than asphalt binder. Therefore, when asphalt binder, water and aggregate are in contact with each other, water changes the system's free energy to reach a condition with the lowest energy level which makes stripping happens. Because, the lower amount of free adhesion energy with the presence of water, reaching the condition with the lowest energy is occurred more rapidly. As it can be realized from the Table 5, using PP has caused the free adhesion energy of asphalt binder and aggregate to increase slightly; this clearly shows that the tendency of the system for stripping and reaching to the stable state with the lowest energy will be decreased. The increase in the amount of PP has caused this amount to be even more and the stripping potential to be decreased. The absolute value of the free debonding energy is shown in Table 6.

Table 6 Free adhesion energy $\left(\mathrm{ergs} / \mathrm{cm}^{2}\right)$

\begin{tabular}{|c|c|c|c|c|c|}
\hline Aggregate & Asphalt binder & Asphalt binder-aggregate & $\begin{array}{l}\text { Asphalt binder-aggregate } \\
\text { in the presence of water }\end{array}$ & Water-aggregate & Asphalt binder-water \\
\hline \multirow{4}{*}{ Granite } & Base asphalt binder & 138.14 & -132.37 & \multirow{3}{*}{359.81} & 55.90 \\
\hline & Modified asphalt binder with $2 \%$ PP & 149.84 & -131.04 & & 66.27 \\
\hline & Modified asphalt binder with $4 \%$ PP & 149.26 & -134.50 & & 69.15 \\
\hline & Base asphalt binder & 153.87 & -130.14 & \multirow{3}{*}{343.30} & 55.90 \\
\hline \multirow{2}{*}{ Limestone } & Modified asphalt binder with $2 \%$ PP & 170.46 & -123.91 & & 66.27 \\
\hline & Modified asphalt binder with $4 \%$ PP & 171.36 & -125.90 & & 69.15 \\
\hline
\end{tabular}


In addition to the free adhesion energy, the primary energy amount needed for the stripping occurrence is also important. Indeed, the primary amount of the energy for stripping equals to an energy that should be consumed for removing asphalt binder-aggregate free adhesion energy. From the Table 6, it is clear that using PP additives has caused the aggregate-asphalt binder free adhesion energy to be significantly decreased. The increase in the amount of PP has caused this amount to be even higher and the stripping potential to be decreased.

The determiner factor in the stripping is the amount of necessary energy for the separation of the asphalt binder from the surface of the aggregate. To determine this energy, the free adhesion energy of the asphalt binder-aggregate (which its unit is (ergs $/ \mathrm{cm}^{2}$ ) should be multiplied by the contact surface of asphalt binder-aggregate. The contact surface of asphalt binder-aggregate is in fact the specified surface area of the aggregates that is the contact surface of asphalt binder-aggregate.

The results of debonding energy are shown in the Table 7. From the table, there is a larger amount of energy needed for the stripping of aggregates from the asphalt binder in the prepared samples with lime aggregates. This process shows that the probability of the occurrence of the stripping in the samples which are cast with limestone aggregate is lower. Also, using PP increases the energy needed for stripping when compared to the samples prepared with basic asphalt binder. This fact causes this expectance to be present that using PP causes a higher resistance of asphalt binder against separation from the surface of the aggregate.

High cost, high temperature sensitivity, low ageing resistance, poor storage stability and limited improvement in elasticity are among the challenges that researchers have encountered in the field of asphalt modification with polymers. According to the reports, ageing propensity, that could significantly challenge unsaturated polymers such as SBS, is caused by combination of asphalt binder oxidation and polymer degradation. The poor compatibility between polymer modifiers and asphalt which is mainly determined by density, molecular weight, polarity, solubility and other properties of polymers and asphalt significantly contribute to the poor storage stability of some polymers. It is believed that the polymer-asphalt compatibility is also affected by chemical structure and reactivity of polymers, which may have a direct relationship with the resulting properties of polymers and modified asphalt. Saturation, sulfur vulcanization, antioxidants, hydrophobic clay minerals, functionalization and application of reactive polymers (which also can be considered as new functionalized products) have been proposed as solutions to the afore-mentioned challenges.

Isocyanate-based polymers such as PP are mainly known as low-molecular-weight polyethylene glycol or polypropylene glycol. It is believed that chemical reactions with isocyanate-based polymers, mainly at high temperatures, can enhance some mechanical properties of asphalt binder. In the presence of isocyanate groups, these polymers usually react with hydroxyl groups in asphalt binder. When treated with water, isocyanate groups and polymers tend to react with each other to modify the asphalt binder at a higher degree. Researchers found that isocyanate-based polymers can increase the viscosity of asphalt binder and improve its storage stability and rutting resistance at high temperatures but are unable to enhance the low-temperature properties as compared to SBS modified asphalt binder. Furthermore, the reactions between isocyanate-based polymers may also lead to the gelation risks of modified asphalt binder.

\section{Conclusions}

Surface free energy method and indirect tensile strength are conducted to evaluating the effect of using Polypropylene as an additive aggregates on moisture damage of asphalt mixtures. By applying the proposed investigation, some important results have been achieved as follows:

1. Adding PP increases the adhesion and cohesion in the mixture and don't allow the asphalt binder removal from aggregates surface and this leads to the fact that the mixtures show a higher resistance against moisture after the cycles of the freeze-thaw as comparison with the control mixtures.

2. The optimal dosage of antistripping incorporation varies based on the type of aggregates and asphalt binder. Also the experiments that are used for determination of moisture

Table 7 Debonding energy in stripping occurrence (ergs/gr)

\begin{tabular}{|c|c|c|c|c|}
\hline Aggregate type & Asphalt binder type & $\begin{array}{l}\text { Specified surface area of the } \\
\text { aggregate }\left(\mathrm{cm}^{2} / \mathrm{gr}\right)\end{array}$ & $\begin{array}{l}\text { Asphalt binder-aggregate's SFE } \\
\left(\mathrm{ergs} / \mathrm{cm}^{2}\right)\end{array}$ & $\begin{array}{c}\text { Needed energy for he stripping of } 1 \text { gram } \\
\text { aggregate (ergs/gr) }\end{array}$ \\
\hline \multirow{3}{*}{ Granite } & Base asphalt binder & \multirow{3}{*}{28200} & 138.14 & 3895476.567 \\
\hline & $\begin{array}{l}\text { Modified asphalt } \\
\text { binder with } 2 \% \text { PP }\end{array}$ & & 149.84 & 4225418.659 \\
\hline & $\begin{array}{l}\text { Modified asphalt } \\
\text { binder with 4\% PP }\end{array}$ & & 149.26 & 4209179.672 \\
\hline \multirow{3}{*}{ Limestone } & Base asphalt binder & \multirow{3}{*}{32100} & 153.87 & 4939096.129 \\
\hline & $\begin{array}{l}\text { Modified asphalt } \\
\text { binder with 2\% PP }\end{array}$ & & 170.46 & 5471743.756 \\
\hline & $\begin{array}{l}\text { Modified asphalt } \\
\text { binder with 4\% PP }\end{array}$ & & 171.36 & 5500499.878 \\
\hline
\end{tabular}


susceptibility can be used for obtaining the optimum percentage of the usage of these materials. The optimum percentage of the additive causes the creation of a layer on the molecules of the asphalt binder which improves adhesion. But the increase in the amount of the antistripping additive creates a second layer that reduces the impact of the first layer.

3. The indirect tensile resistance of the modified samples with PP whether in dry or wet condition has been increased. This is due to the improvement in the free cohesion energy of asphalt binder and also the free adhesion energy of asphalt binder-aggregate.

4. Adding PP significantly increases resistance against moisture damage and increases the amount of the indirect tensile rate in the samples that are modified with this material in comparison with the control mixtures.

5. The use of PP material significantly increases the amount of the total asphalt binder's free non-polar surface energy component. This increase causes non-polar bonds to not be easily separated in the presence of water to be improved and also the resistance of the asphalt mixture against moisture is improved.

6. Using PP increases asphalt binder's free base surface energy component and decreases its free acidic surface energy. This issue increases the base characteristics of asphalt binder that these factors cause a stronger adhesion between asphalt binder and acidic aggregates that are susceptible to moisture damage.

7. PP increases the SFE of the asphalt binder which indicates the reduction of the rapture potential in asphalt binder membrane and mastic.

8. Aggregates with high polar energy cause asphalt binder to have a non-polar state, to cover aggregates with difficulty. Modification with PP changes asphalt binder's characteristics and increases their coating ability.

9. Modification with PP increases the free adhesion energy which tests the adhesion between asphalt binders and aggregates and decreases the potential of separation of binder from surface unit of the aggregate.

10. Using PP decreases the amount of rapture energy (free adhesion energy) in the presence of water. This causes the system to be at a more stable level in terms of thermodynamic and it also decreases the stripping occurrence probability.

11. The performance of limestone against moisture in the presence of water is relatively better than granite due to the fact that it has higher free adhesion energy with asphalt binder. Using PP has decreased the asphalt binder-aggregate's SFE when subjected to the water. This issue clearly exemplifies the fact that the adhesion between asphalt binder and aggregate in the presence of water has been increased and the probability of moisture damage will be decreased. This increasing is more revealing in the resistance of the samples made by granite against the moisture damage.

\section{References}

[1] Hicks, R. G., Santucci, L., Aschenbrener, T. "Introduction and Seminar Objectives". In: Moisture sensitivity of asphalt pavements: A national seminar. pp. 2-21, San Diego. California.2003. http://onlinepubs.trb.org/ onlinepubs/conf/reports/moisture/00_FRONT.pdf

[2] Apeagyei, A. K., Grenfell, J. R., Airey, G. D. "Influence of aggregate absorption and diffusion properties on moisture damage in asphalt mixtures". Road Materials and Pavement Design, 16(sup1), pp. 404-422, 2015. https://doi.org/10.1080/14680629.2015.1030827

[3] Hamedi, G. H., Moghadas Nejad, F., Oveisi, K. "Estimating the moisture damage of asphalt mixture modified with nano zinc oxide". Materials and Structures, 49(4), pp. 1165-1174, 2016.

https://doi.org/10.1617/s11527-015-0566-X

[4] Apeagyei, A. K., Grenfell, J. R., Airey, G. D. "Moisture-induced strength degradation of aggregate-asphalt mastic bonds". Road Materials and Pavement Design, 15(sup1), pp. 239-262, 2014. https://doi.org/10.1080/14680629.2014.927951

[5] Hicks, R. G. "Moisture damage in asphalt concrete". Rep. NCHRP 175. Transportation Research Board, Washington, DC, 1991.

[6] Hamedi, G. H., Nejad, F. M. "Use of aggregate nano coating to decrease moisture damage of hot mix asphalt". Road Materials and Pavement Design, 17(1) pp. 32-51, 2016.

https://doi.org/10.1080/14680629.2015.1056215

[7] Yusoff, N. I. M., Breem, A. A. S., Alattug, H. N. M., Hamim, A., Ahmad, J. "The effects of moisture susceptibility and ageing conditions on nanosilica/polymer-modified asphalt mixtures". Construction and Building Materials, 72, pp. 139-147, 2014.

https://doi.org/10.1016/j.conbuildmat.2014.09.014

[8] Tarefder, R. A., Zaman, A. M. "Nanoscal eevaluation of moisture damage in polymer modified asphalts". Journal of Materials in Civil Engineering, 22(7), pp. 714-725, 2009.

https://doi.org/10.1061/(ASCE)MT.1943-5533.0000072

[9] Hamedi, G. H., Moghadas Nejad, F., Oveisi, K. "Investigating the effects of using nanomaterials on moisture damage of HMA". Road Materials and Pavement Design, 16(3), pp. 536-552, 2015.

https://doi.org/10.1080/14680629.2015.1020850

[10] Arabani, M., Roshani, H. Hamedi, G. H. "Estimating moistures ensitivity of warm mix asphalt modified with zycosoil as an antistrip agent using surface free energy method". Journal of Materials in Civil Engineering, 24(7), pp. 889-897, 2012.

https://doi.org/10.1061/(ASCE)MT.1943-5533.0000455

[11] Hesami, S., Roshani, H., Hamedi, G. H., Azarhoosh, A. R. "Evaluate the mechanism of the effect of hydrated lime on moisture damage of warm mix asphalt". Construction and Building Materials, 47, pp. 935-941, 2013.

https://doi.org/10.1016/j.conbuildmat.2013.05.079

[12] Moghadas Nejad, F., Hamedi, G. H., Azarhoosh, A. R. "Use of surface free energy method to evaluate effect of hydrate lime on moisture damage in hot-mix asphalt". Journal of Materialsin Civil Engineering, 25(8), pp. 1119-1126, 2012. https://doi.org/10.1061/(ASCE)MT.1943-5533.0000650

[13] Arabani, M., Hamedi, G. H. "Using the surface free energy method to evaluate the effects of liquid antistrip additives on moisture sensitivity in hot mix asphalt". International Journal of Pavement Engineering, 15(1), pp. 66-78. 2014. https://doi.org/10.1080/10298436.2013.778410

[14] Poulikakos, L. D., Partl, M. N. "Investigation of porous asphalt microstructure using optical and electron microscopy". Journal of microscopy, 240(2), pp. 145-154, 2010.

https://doi.org/10.1111/j.1365-2818.2010.03388.x 
[15] Moghadas Nejad, F., Arabani, M., Hamedi, G. H., Azarhoosh, A. R. "Influence of using polymeric aggregate treatment on moisture damage in hot mix asphalt". Construction and Building Materials, 47, pp. 1523 1527, 2013.

https://doi.org/10.1016/j.conbuildmat.2013.06.060

[16] Moghadas Nejad, F., Azarhoosh, A. R., Hamedi, G. H., Azarhoosh, M. J. "Influence of using nonmaterial to reduce the moisture susceptibility of hot mix asphalt". Construction and Building Materials, 31, pp. 384-388, 2012. https://doi.org/10.1016/j.conbuildmat.2012.01.004

[17] Sebaaly, P., Little, D. N., Epps, J. "The benefits of hydrated lime in hot mix asphalt". National Lime Association, Arlington, 2006. http://citeseerx.ist. psu.edu/viewdoc/download?doi=10.1.1.508.3233\&rep=rep1\&type=pdf

[18] Petersen, J. C. "A review of the fundamentals of asphalt oxidation: chemical, physicochemical, physical property, and durability relationships". Transportation Research E-Circular, (E-C140), 2009. http://onlinepubs. trb.org/onlinepubs/circulars/ec140.pdf

[19] Souliman, M. I., Hajj, E. Y., Sebaaly, P. E. "Impact of antistrip additives on the long-term aging rheological properties of asphalt binders". Journal of Materials in Civil Engineering, 27(8), 2015. https://doi.org/10.1061/(ASCE)MT.1943-5533.0001111

[20] Tohme, P., Sebaali, P. E., Hajj, E. Y., Johnston, D. "Effectiveness of antistrip additives for bitumen ous mixtures". International Journal of Pavements, 3(2), pp. 50-62, 2004.

[21] Sebaaly, P. E., Little, D. N., Hajj, E. Y., Bhasin, A. "Impact of lime and liquid antistrip agents on properties of Idaho hot-mix asphalt mixture". Transportation Research Record: Journal of the Transportation Research Board, 1998, pp. 65-74, 2007. https://doi.org/10.3141/1998-08

[22] Thomas, K. P., McKay, J. F., Branthaver, J. F. "Surfactants in aged asphalt and impact $\mu$ on moisture susceptibility of laboratory-prepared mixes". Road Materials and Pavement Design, 7(4), pp. 477-490, 2006. https://doi.org/10.1080/14680629.2006.9690047

[23] Griflith, A. "The phenomena on of rupture and flow in solids". Philosophical Transactions of the Royal Society A, 221, pp. 582-593, 1921. https://doi.org/10.1098/rsta.1921.0006

[24] Schapery, R. A. "Correspondence principles and a generalizedJ integral for large deformation and fracture analysis of viscoelastic media". International Journal of Fracture, 25(3), pp. 195-223, 1984. https://doi.org/10.1007/BF01140837

[25] Cheng, D. "Surface Free Energy of Asphalt-Aggregate System and Performance Analysis of Asphalt Concrete". Ph.D. thesis, Texas A\&M University, p. 167, 2002.

[26] Bhasin, A., Masad, E., Little, D. N., Lytton, R. L. "Limits on adhesive bond energy for improved resistance of hot-mix asphalt to moisture damage". Transportation Research Record: Journal of the Transportation Research Board, 1970, pp. 3-13, 2006.

https://doi.org/10.3141/1970-03

[27] Masad, E., Zollinger, C., Bulut, R., Little, D. N., Lytton R. L. "Characterization of HMA moisture damage using surface energy and fracture properties". Journal of the Association of Asphalt Paving Technologists, 75, pp. 713-754, 2006.

[28] Bhasin, A., Little, D. N., Bommavaram, R., Vasconcelos, K. "A framework to quantify the effect of healing in bituminous materials using material properties". Road Materials and Pavement Design, 9(sup1), pp. 219-242, 2008 https://doi.org/10.1080/14680629.2008.9690167

[29] Howson, J., Bhasin, A., Masad, E., Lytton R. L. "Development of a database for surface energy of aggregates and asphalt binders". Federal Highway Administration, Texas Dept. of Transportation, Austin, TX, Rep. FHWA/TX-09/5-4524-01-1, 2009. https://static.tti.tamu.edu/tti. tamu.edu/documents/5-4524-01-1.pdf
[30] Little, D. N., Bhasin, A. Hefer, A. "Using surfaceenergy measurements to select materials for asphalt pavement". National Cooperative Highway Research Program, Washington, DC, Rep. NCHRP 9-37, 2006.

[31] Kim, S. H., Jeong, J. H., Kim, N. "Use of surface free energy properties to predict moisture damage potential of asphalt concrete mixture in cyclic loading condition". KSCE Journal of Civil Engineering, 7(4), pp. 381$387,2003$. https://doi.org/10.1007/BF02895836

[32] Lytton, R. L., Masad, E.,Zollinger, C., Bulut, R., Little, D. N. "Measurements of surface energy and its relationship to moisture damage". Texas Transportation Institute, Texas A\&M Univ., College Station, United States, Rep. FHWA/TX-05/0-4524-2, 2005. http://tti.tamu.edu/documents/0-4524-2.pdf

[33] Hamedi, G. H.,Moghadas Nejad, F. "Using energy parameters based on the surface free energy concept to evaluate the moisture susceptibility of hot mix asphalt". Road Materials and Pavement Design, 16(2), pp. 239-255, 2015.

https://doi.org/10.1080/14680629.2014.990049

[34] Moghadas Nejad, F.,Tanzadeh, R., Tanzadeh, J., Hamedi, G. H. "Investigating the effect of nanoparticles on the rutting behaviour of hot-mix asphalt". International Journal of Pavement Engineering, 17(4), pp. 353 $362,2016$.

https://doi.org/10.1080/10298436.2014.993194

[35] Hefer, A. W., Bhasin, A., Little, D. N. "Bitumen surface energy characterization using a contact angle approach". Journal of Materials in Civil Engineering, 18(6), pp. 759-767, 2006. https://doi.org/10.1061/(ASCE)0899-1561(2006)18:6(759)

[36] Little, D. N., Bhasin, A. "Using surface energy measurements to select materials for asphalt pavement". National Cooperative Highway Research Program, Washington, DC, Rep. NCHRP Project 9-37, 2006. 